\title{
Melatonin improves the efficiency of super-ovulation and timed artificial insemination in sheep
}

\author{
Yukun Song ${ }^{1}$, Hao $\mathrm{Wu}^{2}$, Xuguang Wang ${ }^{1}$, Aerman Haire ${ }^{1}$, Xiaosheng Zhang ${ }^{3}$, Jinlong Zhang ${ }^{3}$, Yingjie Wu ${ }^{2}$, \\ Zhengxing Lian ${ }^{2}$, Juncai Fu ${ }^{2}$, Guoshi Liu ${ }^{\text {Corresp., }}{ }^{2}$, Abulizi Wusman ${ }^{\text {Corresp. } 1}$ \\ ${ }^{1}$ College of Animal Science, Xinjiang Agricultural University, Urumqi, Xinjiang, China \\ National Engineering Laboratory for Animal Breeding, Key Laboratory of Animal Genetics and Breeding of the Ministry of Agriculture, Beijing Key \\ Laboratory for Animal Genetic Improvement, College of Animal Science and Technology, China Agricultural University, Beijing, Beijing, China \\ 3 Institute of Animal Husbandry and Veterinary, Academy of Agricultural Sciences of Tianjin, Tianjin, Tianjin, China \\ Corresponding Authors: Guoshi Liu, Abulizi Wusman \\ Email address: gshliu@cau.edu.cn, abulizi68@126.com
}

It has been well proved that melatonin participates in the regulation of the seasonal reproduction of ewes. However, the effects of short term treatment of melatonin on ewe's ovulation are still to be clarified. In this study, the effects of melatonin on the number of embryo s harvested from superovulation, and the pregnant rate in recipients after embryo transferred have been investigated. Hu sheep with synchronous estrus treatment were given melatonin subcutaneously injection (0, 5, and $10 \mathrm{mg} / \mathrm{ewe}$, respectively). It was found that $\mathrm{t}$ he estrogen level in the group of $5 \mathrm{mg}$ melatonin was significantly higher than that of other two groups a t the time of sperm insemination $(p<0.05)$. The pregnant rate and number of lambs in the group of $5 \mathrm{mg}$ melatonin treatment was also significantly higher than that of the rests of the groups $(P<0.05)$. In another study, 31 Suffolk ewes as donors and 103 small-tailed han sheep ewes as recipients were used to produce pronuclear embryo and embryo transfer. Melatonin $(5 \mathrm{mg}$ ) was given to the donors during estrus. The results showed that, the number of pronuclear embryos and the pregnancy rate were also significantly higher in melatonin group than that in the control group. In addition, 28 donors and 44 recipient ewes were used to produce morula/blastocyst and embryo transferring. Melatonin ( $5 \mathrm{mg}$ ) was given during estrus. The total number of

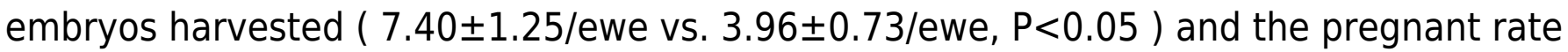
$(72.3 \pm 4.6 \%$ vs. $54.7 \pm 4.0 \%, P<0.05)$ and number of lambs were also increased in melatonin group compared to the control group. Collectively, the results have suggested that melatonin treatment 36 hours after CIDR withdrawal could promote the number and quality of embryos in the in vivo condition and increased the pregnant rate and number of lambs. 
1 Melatonin Improves the Efficiency of Super-ovulation and Timed Artificial Insemination in Sheep

2 Yukun Song ${ }^{1,2 \#}$, Hao $\mathrm{Wu}^{2 \#}$, Xuguang Wang ${ }^{1}$, Aerman Haire ${ }^{1}$, Xiaosheng Zhang ${ }^{3}$, Jinlong Zhang ${ }^{3}$, Yingjie

$3 \mathrm{Wu}^{2}$, Zhengxing Lian ${ }^{2}$, Juncai $\mathrm{Fu}^{2}$, Guoshi Liu ${ }^{1,2^{*}}$, Abulizi Wusiman ${ }^{1 *}$

5 1.College of Animal Science, Xinjiang Agricultural University, Urumqi, Xinjiang 830052, China;

6 2.National Engineering Laboratory for Animal Breeding, Key Laboratory of Animal Genetics and Breeding

7 of the Ministry of Agriculture, Beijing Key Laboratory for Animal Genetic Improvement, College of

8 Animal Science and Technology, China Agricultural University, Beijing, 100193, China;

9 3.Institute of Animal Husbandry and Veterinary, Academy of Agricultural Sciences of Tianjin, 10 Tianjin,300381 China.

11

12

* Corresponding author: Abulizi Wusiman, E-mail: abulizi68@126.com; Guoshi Liu, E-mail:

13 gshliu@cau.edu.cn.

14 \# these authors contribute equally to this article.

15

16

17

18

19

20

21

22

23

24

25

26

27

28

29

30

31

32 
33 Abstract: It has been well proved that melatonin participates in the regulation of the seasonal reproduction

34 of ewes. However, the effects of short term treatment of melatonin on ewe's ovulation are still to be 35 clarified. In this study, the effects of melatonin on the number of embryos harvested from superovulation, 36 and the pregnant rate in recipients after embryo transferred have been investigated. Hu sheep with 37 synchronous estrus treatment were given melatonin subcutaneously injection $(0,5$, and $10 \mathrm{mg} / \mathrm{ewe}$, 38 respectively). It was found that the estrogen level in the group of $5 \mathrm{mg}$ melatonin was significantly higher 39 than that of other two groups at the time of sperm insemination $(p<0.05)$. The pregnant rate and number 40 of lambs in the group of $5 \mathrm{mg}$ melatonin treatment was also significantly higher than that of the rests of the 41 groups $(P<0.05)$. In another study, 31 Suffolk ewes as donors and 103 small-tailed han sheep ewes as 42 recipients were used to produce pronuclear embryo and embryo transfer. Melatonin (5 $\mathrm{mg}$ ) was given to 43 the donors during estrus. The results showed that, the number of pronuclear embryos and the pregnancy 44 rate were also significantly higher in melatonin group than that in the control group. In addition, 28 donors 45 and 44 recipient ewes were used to produce morula/blastocyst and embryo transferring. Melatonin (5 mg) 46 was given during estrus. The total number of embryos harvested (7.40 \pm 1.25 /ewe vs. 3.96 $\pm 0.73 /$ ewe, $47 \mathrm{P}<0.05)$ and the pregnant rate $(72.3 \pm 4.6 \%$ vs.54.7 $\pm 4.0 \%, \mathrm{P}<0.05)$ and number of lambs were also increased 48 in melatonin group compared to the control group. Collectively, the results have suggested that melatonin treatment 36 hours after CIDR withdrawal could promote the number and quality of embryos in the in vivo condition and increased the pregnant rate and number of lambs.

51

52

53

54

55

56

57

58

59

60

61

62

63

64

65

66 


\section{Introduction}

68 The estrous cycles of most sheep are regulated by the switch of seasons. With the reduced photoperiod and

69 increased melatonin level, ewes adjust GnRH level and estrus cycles [1]. Thus, as a photoperiodic signal

70 molecule melatonin regulates the reproductive activity of ewes. Melatonin is also a potent antioxidant and

71 free radical scavenger [2]. Under the consideration, melatonin can also protect the reproductive tissues and

72 organs. A various of ROS (reactive oxygen species such as $\mathrm{OH}^{-}$- and $\mathrm{O}_{2}^{-}$) will damage the DNA and the

73 lipid of cell membrane, accelerate apoptosis in reproductive system [3]. For example, oxidative stress

74 induces two cell developmental block, apoptosis and infertility [4-5]. The reason is that oxidative stress

75 reduces the quality of oocytes which is an important factor for sheep fertility. Melatonin scavenges $\mathrm{OH}^{-}$,

$76 \mathrm{H}_{2} \mathrm{O}_{2}$ and other reactive oxygen species, therefore, it contributes to effectively reduce oxidative DNA

77 damage and cell apoptosis during ovulation [6]. Melatonin also reduces oxidative damage to mitochondrial

78 DNA [7]. It was reported that, melatonin preserved the normal distribution of mitochondria, mitochondrial

79 DNA copy number membrane potential (MMP), and ATP level [8]. Melatonin improves the quality of

80 bovine oocyte, oocyte maturation, efficiency of in vitro fertilization and embryo development [9].

81 Melatonin administration improved the conception rates in mice and cows [10]. Melatonin added during

82 culture of mouse prokaryotic embryos significantly increased blastocyst rate, pregnancy rate after transplantation, average number of offspring and survival rate of offspring [11]. For deer, melatonin

84 subcutaneous implantation also improved the quantity and quality of super ovulatory oocytes [12].

85 Therefore, melatonin is probably the key factor to improve fecundity by improving the quality of oocytes

86 in mammals.

87 Melatonin also plays an important role in the establishment and maintenance of pregnancy in animals. In mouse, extremely high expression of melatonin receptor 1 (MT1) was observed in granulosa cells after

89 human chorionic gonadotropin (hCG) treatment [12]. At the same time, melatonin synthetic enzyme in 90 cumulus cells was upregulated by hCG injection and high level of melatonin in follicle fluid was detected

$91[13]$ and this was observed also in porcine follicle fluid [14]. Further study demonstrated that melatonin 92 and its receptor MT1 regulated the downstream signaling pathway of hCG (LH) including the luteinization 93 of granulosa cells in mice [12]. The deletion of MT1 receptor severely impairs the fertility of mice due to 94 reduced oocyte number and quality [15].

95 In addition, melatonin subcutaneous implantation in sheep increase the number of corpus luteum and 96 pregnancy rate [16]. However, there is no report regarding the effect of melatonin short term administration 97 during estrus on the reproductive efficiency and embryo production in animals, particularly in ewes.

98 Therefore, this study was conducted to test whether melatonin short term administration can improve the 99 synchronized estrus pregnant rate and the production of both pronuclear and morula/blastocyst embryos in 100 ewes. 


\section{Materials and methods}

\section{Chemicals}

103 CIDRs (Controlled Internal Drug Release) which contains $300 \mathrm{mg}$ progesterone were purchased from Pfizer

104 Animal Health (New Zealand). Follicle stimulating hormone (FSH), luteinizing hormone (LH) and 105 pregnant mare serum gonadotropin (PMSG) were from Ningbo Sansheng Pharmaceutical Industry Co., 106 Ltd.(China). Melatonin and all other reagents, unless specified, were purchased from Sigma-Aldrich Co. 107 (USA).

\section{Animals}

109 Female sheep (Hu, Suffolk and Small-tailed Han) from Aoxin Animal Husbandry (Beijing, China) and 110 Zhenxin Farmers's Professional Association Organization (Uygur Autonomous Region, China), at the age 111 of 2-4 years old with normal reproductive cycle, healthy and generally the similar body weight were 112 selected for the experiments. All experimental protocols concerning the handling of animals were 113 performed in accordance with the requirements of the Institutional Animal Care and Use Committee at the 114 Xinjiang Agricultural University(permition number:2017003).

\section{Experiment design}

116 Experiment 1: fifty-seven ewes were randomly divided into three groups and then treated with CIDRs to 117 induce synchronized estrus. All the ewes assess freely to the same feed and drink water. The CIDRs were 118 removed 13 days later, blood samples were collected and the ewes were injected with PMSG. The second 119 blood collection was conducted 36 hours after the CIDR removal and melatonin $(0,5,10 \mathrm{mg}$,) was 120 subcutaneously injected at the same time, respectively. Artificial insemination was conducted 48 hours after 121 the removal of the CIDR, and the third blood collection was conducted. B-ultrasound examination was 122 conducted 45 days after artificial insemination and ewes with pregnancy were recoded.

123 Experiment 2: thirty-one Suffolk ewes as donors and 103 Small-tailed Han ewes as recipients were 124 selected, and the donors were divided into two groups and underwent the stimulated ovulation procedure. 125 Among the donors, 13 ewes were subcutaneously injected with 5mg melatonin 36 hours after the CIDR 126 was removed and 18 ewes served as control group, and LH was injected to all the donors at the same time. 127 Then the donors were inseminated by laparoscope, and 10 hours later pronuclear embryos were surgically 128 collected, and the pronuclear embryos were observed by stereomicroscope and selected depends on the 129 morphology. The number of corpora luteal (CL) and embryos harvested were recorded. The embryos with 130 normal morphology were transferred into the oviduct of recipients. The examination of pregnancy was 131 performed using B-ultrasound 45 days after embryo transfer.

132 Experiment 3: twenty-eight Suffolk ewes as donors and 44 Small-tailed Han ewes as recipient were 133 selected and divided into two groups randomizedly. The donor ewes were treated to induce superovulation, 
134 and 36 hours after CIDR removal LH and melatonin ( $5 \mathrm{mg}$ ) was subcutaneously injected into donors at the 135 same time. Six days after artificial insemination by laparoscopic, morula or blastocyst were surgically 136 harvested from the uterine horn of the donor, and the number of CL and embryos were recorded. The 137 recipient was surgically operated with the laparoscopic surgery to find the uterine horn, finally the embryo 138 was transplanted into the uterine horn from the $5 \mathrm{~cm}$ junction between the uterus and the fallopian tube by 139 the the transplantation pipette. The examination of pregnancy was performed using B-ultrasound 45 days 140 after embryo transfer.

\section{Semen preparation}

142 In this study, fresh semen was collected from male sheep of black Suffolk using a vaginal prosthesis, and

143 then the semen was diluted and store at $36^{\circ} \mathrm{C}$. Fresh semen is injected into the uterine horn when its vitality 144 reaches 0.6 or more by laparoscopic insemination.

145 Blood sample collection and hormones analyze

146 For Experiment 1, 5ml blood samples was collected and stored in $-80^{\circ} \mathrm{C}$ freezer for measurement. 147 Hormones level were determined was conducted by Beijing North Biotechnology Research Institute by 148 radioimmunoassay.

\section{Statistical analysis}

150 All data were presented as means \pm SEM. The data were analyzed using ANOVA and followed by LSD 151 and Duncan tests for the differences between treatments (SPSS software), $P<0.05$ was used as the criterion 152 for the significance of the difference.

153 Results

154 Effects of melatonin injection on hormones

155 Firstly, the effects of melatonin on FSH, LH and E2 were evaluated at 3 different time points (Table 1). At 156 the time of artificial insemination, the melatonin in the serum of ewes in $5 \mathrm{mg}$ group $(509.0 \pm 67.5 \mathrm{pg} / \mathrm{ml})$ 157 was significantly higher than that of the other control group $(330.2 \pm 38.7 \mathrm{pg} / \mathrm{ml})(p<0.05)$. But there was no 158 difference in melatonin levels between the three groups at the time of CIDR withdrawal and estrus. The 159 FSH level in the control group was always in a high level, but the increase of FSH from estrus to 160 insemination $(0.2 \mathrm{mIU} / \mathrm{ml})$ in the $5 \mathrm{mg}$ group was significantly higher than that in the other two groups $161(0.03 \mathrm{mIU} / \mathrm{ml}$ and $0.09 \mathrm{mIU} / \mathrm{ml}, p<0.05)$. LH level was increased from CIDR withdrawal to estrus, and 162 gradually decreased after the peak level. LH level in the $5 \mathrm{mg}$ group $(4.59 \pm 0.4 \mathrm{mIU} / \mathrm{ml})$ was significantly 163 higher than that in the other two groups $(4.02 \pm 0.3 \mathrm{mIU} / \mathrm{ml}, 4.27 \pm 0.3 \mathrm{mIU} / \mathrm{ml})$ at the time of insemination $164(p<0.05)$. Progesterone concentration in the $10 \mathrm{mg}$ group was the highest, followed by a downward trend, 165 significantly higher than that in the control group at the time of withdrawal CIDR and estrus $(p<0.05)$, and 166 significantly higher than $5 \mathrm{mg}$ group at the time of estrus $(p<0.05)$. The concentration of progesterone of 
167 the $10 \mathrm{mg}$ treated group was highest at the time of insemination, but there was no significant difference

168 between the two groups ( $p>0.05)$. There was no difference in estradiol level between the two groups at the

169 time of CIDR withdrawal and estrus. At the time of insemination, $5 \mathrm{mg}$ group $(19.2 \pm 2.7 \mathrm{pg} / \mathrm{ml})$ was

170 significantly higher than the other two groups $(13.8 \pm 1.8 \mathrm{pg} / \mathrm{ml}, 14.1 \pm 2.9 \mathrm{pg} / \mathrm{ml}, p<0.05)$.

\section{Effects of melatonin on the pregnancy and number of lambs born in sheep}

172 Melatonin was subcutaneously injected to the ewes 36 hours after the withdrawal of CIDRs, at the dosage

173 of $5 \mathrm{mg}$ (21 ewes), $10 \mathrm{mg}$ (20 ewes), and control group (18 ewes). Then the ewes received artificial

174 insemination and the pregnancy was examined 45 days later. As shown in Table 2, the pregnancy rate of

175 ewes with melatonin $5 \mathrm{mg}$ injection $(66.67 \pm 4.76 \%)$ was significantly higher than that of the other two

176 groups, respectively $(40.48 \pm 6.30 \%, 37.62 \pm 5.78 \%, p<0.05)$, and there was no significant difference

177 between the $10 \mathrm{mg}$ group and the control group. As for the number of lambs born, there was no difference

178 among all three groups $(p>0.05)$.

\section{Effects of melatonin on embryo production and pregnancy rate in sheep}

180 To know how melatonin affects sheep reproductive activity, the pronuclear embryos and blastocysts of the 181 donors were harvested and then transferred to recipients. It was found that melatonin injection slightly 182 increased the number of CL $(8.78 \pm 1.78$ vs $8.44 \pm 1.13)$ and pronuclear embryos $(8.8 \pm 1.9 /$ ewe vs $1838.3 \pm 1.0 /$ ewe), $(p>0.05)$ (Table 3). However, the pregnancy rate of embryos and birth rate of lambs in 184 melatonin $5 \mathrm{mg}$ group were significantly higher than that of the control group $(43.3 \pm 6.1 \%$ vs $25.3 \pm 4.9 \%$, 185 and $54.0 \pm 4.0 \%$ vs $27.7 \pm 9.0 \% p<0.05$ ) (Table 4). During the period of estrus, the donor who received 186 melatonin treatment significantly increased the total number of morula embryo/blastocyst at 6 days after 187 insemination ( $7.4 \pm 1.3$ /ewe, $4.0 \pm 0.7 /$ ewe, $p<0.05)$ (Table 5), and also the pregnancy rate was significantly 188 increased after embryo transfer compared to the control group $(72.3 \pm 4.6 \%$ vs $54.7 \pm 4.0 \%, p<0.05)$, for 189 the number of lambs the ewes born, there was no difference among two groups ( $p>0.05)$ (Table 6).

\section{Discussion}

192 Current study has demonstrated that short term melatonin treatment during estrus elevates estradiol and LH 193 levels, improves oocyte quality and leads to the increase of the pregnant rate in ewes. These observations 194 are consistent with previous studies which indicates that melatonin treatment increases serum LH [17] and 195 progesterone levels in sheep [18]. Wang et al [19] found that the melatonin level decreased after the removal 196 of CIDR in deer and this is similar to our observation in the current study. We also observed that melatonin 197 administration significantly increased serum melatonin level, it enhanced the LH and progesterone levels 198 in turn, subsequently led to increase in the numbers of embryos and better pregnant rate.

199 Ovulation is similar to inflammatory reaction that produces a large amount of ROS and reactive nitrogen 200 (RNS) [20]. In the early pregnancy, ROS inhibits progesterone production from corpus luteal cells causes 
201 luteal CL regression [21], and also induces ovarian cell apoptosis [22]. As a potent antioxidant, melatonin 202 detoxifies ROS including $\mathrm{OH}^{-}, \mathrm{O}^{2-}$ and $\mathrm{H}_{2} \mathrm{O}_{2}$ and reduces the oxidative damage of ovarian cells [23] and 203 thus, improves the fertility and fecundity of sheep by improving the survival rate of corpus luteum and 204 embryos [24]. Numerous studies have proved that melatonin promotes the development of oocytes and 205 embryos in sheep [25], pigs [26], cattle [27], mice [28] and humans [29] in the in vitro environment by 206 scavenging ROS or.

207 Luridiana et al reported that the melatonin implantation in ewe at the age of 5-6 with 3.5-4.0 body 208 condition score (BSC) in spring improved fertility of ewes [30]. In our study, the pregnant rate of ewes 209 received single melatonin injection was significantly increased as well as both pronuclear embryos and 210 blastocysts compared with the control group. Yang et al [31] observed that the melatonin injection before 211 mating improved the pregnancy rate of Holstein cows preluded with elevated serum melatonin and 212 progesterone levels. In our experiment, the progesterone level in serum did not change after melatonin 213 treatment, but the estradiol was increased. Melatonin may benefit follicular development, and then increases 214 estradiol synthesis to promote ovulation in female sheep.

215 In this study, we observed the effects of melatonin to synchronize estrous in ewe, especially in the 216 donor ewes to benefit the embryo transplantation. Short term of melatonin treatment during estrus might 217 improve the uterine environment of ewe and significantly increased the pregnant rate. In addition, melatonin 218 improves the quality and quantity of embryos and this may also contribute to the increased pregnant rate.

219 These data provide strong support for the application of melatonin in sheep to improve the reproductive 220 outcome industrially.

\section{Conclusion:}

222 Melatonin at $5 \mathrm{mg}$ subcutaneously injected into the neck during estrus would increase the level of 223 melatonin and estradiol in the blood of ewe, and melatonin promoted embryo production and the pregnancy 224 rate in the awes naturally mated or embryo transfer. Meanwhile, melatonin had beneficial effects on 225 recipients for embryo transfer. Altogether, melatonin could be used to the improve the number of lambs.

226

227

228

229

230

231 [1] Ortavant R, Bocquier F, Pelletier J, et al. Seasonality of reproduction in sheep and its control by 232 photoperiod[J]. Aust J Biol Sci. 1988, 41(1): 69-85.

233 [2] Tan DX, Chen LD, Poeggeler B, L Manchester C, Reiter RJ. Melatonin: a potent, endogenous hydroxyl 234 radical scavenger. Endocr. J. 1993, 1: 57-60. 
235 [3] Agarwal A, Gupta S, Sharma R K. Role of oxidative stress in female reproduction[J]. Reprod Biol 236 Endocrinol. 2005, 3: 28.

237 [4]Tatone C, Amicarelli F. The aging ovary - the poor granulosa cells. Fertility and sterility. 2013 Jan 238 1;99(1):12-7.

239 [5] Devine P J, Perreault S D, Luderer U. Roles of reactive oxygen species and antioxidants in ovarian 240 toxicity[J]. Biol Reprod. 2012, 86(2): 27.

241 [6] Miyamoto K, Sato E F, Kasahara E, et al. Effect of oxidative stress during repeated ovulation on the 242 structure and functions of the ovary, oocytes, and their mitochondria[J]. Free Radic Biol Med. 2010, 49(4): 243 674-681.

244 [7] Galano A, Tan D X, Reiter R J. Melatonin: A Versatile Protector against Oxidative DNA Damage[J]. 245 Molecules. 2018, 23(3).

246 [8] Liang S, Jin Y X, Yuan B, et al. Melatonin enhances the developmental competence of porcine somatic 247 cell nuclear transfer embryos by preventing DNA damage induced by oxidative stress[J]. Sci Rep. 2017, $248 \quad 7(1): 11114$.

249 [9] He C, Wang J, Zhang Z, et al. Mitochondria Synthesize Melatonin to Ameliorate Its Function and 250 Improve Mice Oocyte's Quality under in Vitro Conditions[J]. Int J Mol Sci. 2016, 17(6).

251 [10] Guo XH, Li YH, Zhao YS, et al. Antiaging effects of melatonin on the myocardial mitochondria of 252 rats and associated mechanisms[J]. Mol Med Rep. 2017, 15(1): 403-410.

253 [11] Yang M, Tao J, Chai M, et al. Melatonin Improves the Quality of Inferior Bovine Oocytes and 254 Promoted Their Subsequent IVF Embryo Development: Mechanisms and Results[J]. Molecules. 2017, 255 22(12).

256 [12] He C, Ma T, Shi J, et al. Melatonin and its receptor MT1 are involved in the downstream reaction to 257 luteinizing hormone and participate in the regulation of luteinization in different species[J]. J Pineal Res. 258 2016, 61(3): 279-290.

259 [13] Tian X, Wang F, Zhang L, et al. Melatonin Promotes the In Vitro Development of Microinjected 260 Pronuclear Mouse Embryos via Its Anti-Oxidative and Anti-Apoptotic Effects[J]. Int J Mol Sci. 2017, $26118(5)$.

262 [14] Shi JM, Tian XZ, Zhou GB, Wang L, Gao C, Zhu SE, Zeng SM, Tian JH, Liu GS. Melatonin exists in 263 porcine follicular fluid and improves in vitro maturation and parthenogenetic development of porcine 264 oocytes. Journal of pineal research. 2009,47(4):318-23.

265 [15] Zhang L, Zhang Z, Wang J, Lv D, Zhu T, Wang F, Tian X, Yao Y, Ji P and Liu G. (2019), Melatonin 266 regulates the activities of ovary and delays the fertility decline in female animals via MT1/AMPK pathway. J 267 Pineal Res. Accepted Author Manuscript. doi:10.1111/jpi.12550 
268 [16] Zhang L, Chai M, Tian X, et al. Effects of melatonin on superovulation and transgenic embryo 269 transplantation in small-tailed han sheep (Ovis aries)[J]. Neuro Endocrinol Lett. 2013, 34(4): 294-301.

270 [17] Zarazaga L A, Gatica M C, Celi I, et al. Effect of melatonin implants on sexual activity in 271 Mediterranean goat females without separation from males[J]. Theriogenology. 2009, 72(7): 910-918.

272 [18] Abecia J A, Forcada F, Zuniga O. The effect of melatonin on the secretion of progesterone in sheep 273 and on the development of ovine embryos in vitro[J]. Vet Res Commun. 2002, 26(2): 151-158.

274 [19] Wang L, Zhuo Z Y, Shi W Q, et al. Melatonin promotes superovulation in sika deer (Cervus nippon)[J]. 275 Int J Mol Sci. 2014, 15(7): 12107-12118.

276 [20] Gupta R K, Miller K P, Babus J K, et al. Methoxychlor inhibits growth and induces atresia of antral 277 follicles through an oxidative stress pathway[J]. Toxicol Sci. 2006, 93(2): 382-389.

278 [21] Al-Gubory K H, Garrel C, Faure P, et al. Roles of antioxidant enzymes in corpus luteum rescue from 279 reactive oxygen species-induced oxidative stress[J]. Reprod Biomed Online. 2012, 25(6): 551-560.

280 [22] Korzekwa A J, Okuda K, Woclawek-Potocka I, et al. Nitric oxide induces apoptosis in bovine luteal 281 cells[J]. J Reprod Dev. 2006, 52(3): 353-361.

282 [23] Loren P, Sanchez R, Arias M E, et al. Melatonin Scavenger Properties against Oxidative and 283 Nitrosative Stress: Impact on Gamete Handling and In Vitro Embryo Production in Humans and Other 284 Mammals[J]. Int J Mol Sci. 2017, 18(6).

285 [24] Tamura H, Takasaki A, Taketani T, et al. Melatonin and female reproduction[J]. J Obstet Gynaecol 286 Res. 2014, 40(1): 1-11.

287 [25] Tian X, Wang F, Zhang L, et al. Beneficial Effects of Melatonin on the In Vitro Maturation of Sheep 288 Oocytes and Its Relation to Melatonin Receptors[J]. Int J Mol Sci. 2017, 18(4).

289 [26] Wang T, Gao Y Y, Chen L, et al. Melatonin prevents postovulatory oocyte aging and promotes 290 subsequent embryonic development in the pig[J]. Aging (Albany NY). 2017, 9(6): 1552-1564.

291 [27] Rodrigues-Cunha M C, Mesquita L G, Bressan F, et al. Effects of melatonin during IVM in defined 292 medium on oocyte meiosis, oxidative stress, and subsequent embryo development[J]. Theriogenology. 293 2016, 86(7): 1685-1694.

294 [28] Zhang Y, Li W, Ma Y, et al. Improved development by melatonin treatment after vitrification of mouse 295 metaphase II oocytes[J]. Cryobiology. 2016, 73(3): 335-342.

296 [29] Carlomagno G, Nordio M, Chiu T T, et al. Contribution of myo-inositol and melatonin to human 297 reproduction[J]. Eur J Obstet Gynecol Reprod Biol. 2011, 159(2): 267-272.

298 [30] Luridiana S, Mura M C, Daga C, et al. Melatonin treatment in spring and reproductive recovery in 299 sheep with different body condition score and age[J]. Anim Reprod Sci. 2015, 160: 68-73.

300 [31] Yang M, Shi J, Tian J, et al. Exogenous melatonin reduces somatic cell count of milk in Holstein 301 cows[J]. Sci Rep. 2017, 7: 43280. 
Table $\mathbf{1}$ (on next page)

Effects of melatonin injection on $\mathrm{FSH}, \mathrm{LH}, \mathrm{P}_{4}$ and $\mathrm{E}_{2}$. 
1 Table 1: Effects of melatonin injection on FSH, LH, $\mathrm{P}_{4}$ and $\mathrm{E}_{2}$.

\begin{tabular}{|c|c|c|c|c|c|c|}
\hline Time & Group & $\mathrm{MT}(\mathrm{pg} / \mathrm{ml})$ & FSH (mIU/ml) & $\mathrm{LH}(\mathrm{mIU} / \mathrm{ml})$ & $\mathrm{P}_{4}(\mathrm{mIU} / \mathrm{ml})$ & $\mathrm{E}_{2}(\mathrm{mIU} / \mathrm{ml})$ \\
\hline \multirow{4}{*}{ Withdrew CIDR } & $5 \mathrm{mg}$ & $363.59 \pm 63.87^{\mathrm{a}}$ & $2.04 \pm 0.08^{\mathrm{a}}$ & $4.93 \pm 0.25^{\mathrm{a}}$ & $0.26 \pm 0.04^{\mathrm{ab}}$ & $14.61 \pm 2.56^{\mathrm{a}}$ \\
\hline & $10 \mathrm{mg}$ & $390.69 \pm 64.22^{\mathrm{a}}$ & $2.05 \pm 0.07^{\mathrm{a}}$ & $4.93 \pm 0.34^{\mathrm{a}}$ & $0.30 \pm 0.05^{\mathrm{a}}$ & $15.06 \pm 1.30^{\mathrm{a}}$ \\
\hline & Control & $350.95 \pm 63.16^{\mathrm{a}}$ & $2.16 \pm 0.14^{\mathrm{a}}$ & $4.64 \pm 0.29^{a}$ & $0.21 \pm 0.02^{b}$ & $15.04 \pm 1.39^{a}$ \\
\hline & $5 \mathrm{mg}$ & $458.69 \pm 48.40^{\mathrm{a}}$ & $1.86 \pm 0.09^{b}$ & $5.39 \pm 0.52^{\mathrm{a}}$ & $0.17 \pm 0.02^{\mathrm{b}}$ & $23.11 \pm 3.62^{\mathrm{a}}$ \\
\hline \multirow[t]{3}{*}{ Estrus } & $10 \mathrm{mg}$ & $458.09 \pm 60.60^{\mathrm{a}}$ & $1.79 \pm 0.13^{\mathrm{b}}$ & $5.41 \pm 0.49^{\mathrm{a}}$ & $0.22 \pm 0.02^{\mathrm{a}}$ & $24.49 \pm 2.50^{\mathrm{a}}$ \\
\hline & Control & $393.37 \pm 51.53^{\mathrm{a}}$ & $2.05 \pm 0.15^{\mathrm{a}}$ & $5.26 \pm 0.48^{\mathrm{a}}$ & $0.16 \pm 0.02^{b}$ & $22.96 \pm 2.01^{\mathrm{a}}$ \\
\hline & $5 \mathrm{mg}$ & $509.00 \pm 67.52^{\mathrm{a}}$ & $2.06 \pm 0.13^{\mathrm{a}}$ & $4.59 \pm 0.38^{\mathrm{a}}$ & $0.14 \pm 0.02^{\mathrm{a}}$ & $19.23 \pm 2.66^{\mathrm{a}}$ \\
\hline \multirow[t]{2}{*}{ Insemination } & $10 \mathrm{mg}$ & $457.24 \pm 40.65^{\mathrm{ab}}$ & $1.76 \pm 0.14^{\mathrm{b}}$ & $4.02 \pm 0.27^{\mathrm{b}}$ & $0.18 \pm 0.03^{\mathrm{a}}$ & $13.78 \pm 1.77^{\mathrm{b}}$ \\
\hline & Control & $330.23 \pm 38.72^{\mathrm{b}}$ & $2.14 \pm 0.26^{\mathrm{a}}$ & $4.27 \pm 0.31^{b}$ & $0.14 \pm 0.02^{\mathrm{a}}$ & $14.07 \pm 2.86^{\mathrm{b}}$ \\
\hline
\end{tabular}

2 Note: different letters in the same column at same time point indicate significant difference $(p<0.05)$.

3 
Table 2 (on next page)

Effect of melatonin treatment on pregnancy of ewes 
1 Table 2: Effect of melatonin treatment on pregnancy of ewes

\begin{tabular}{llllc} 
Group & Ewes & Pregnant Ewes & Pregnancy rate & Lambs/ewes (\%) \\
\hline $5 \mathrm{mg}$ & 21 & 14 & $66.67 \pm 4.76^{\mathrm{a}}$ & $40 / 14(285.7 \%)^{\mathrm{a}}$ \\
$10 \mathrm{mg}$ & 20 & 8 & $40.48 \pm 6.30^{\mathrm{b}}$ & $22 / 8(275.0 \%)^{\mathrm{a}}$ \\
Control & 18 & 7 & $37.62 \pm 5.78^{\mathrm{b}}$ & $22 / 7(314.3 \%)^{\mathrm{a}}$
\end{tabular}

2 Note: different letters in the same column indicate significant difference $(p<0.05)$.

3 
Table 3(on next page)

Effect of different treatments on pronuclear embryo production after superovulation of donor ewes 
1 Table 3 Effect of different treatments on pronuclear embryo production after superovulation of donor ewes

\begin{tabular}{ccccc}
\hline Group & Donors & Corpus Luteum & Embryos & Normal Embryos \\
\hline $5 \mathrm{mg}$ & 13 & $8.78 \pm 1.78^{\mathrm{a}}$ & $8.81 \pm 1.86^{\mathrm{a}}$ & $8.81 \pm 1.86^{\mathrm{a}}$ \\
Control & 18 & $8.44 \pm 1.13^{\mathrm{a}}$ & $8.31 \pm 1.00^{\mathrm{a}}$ & $8.31 \pm 1.00^{\mathrm{a}}$ \\
\hline
\end{tabular}

2 Note: different letters in the same column indicate significant difference $(p<0.05)$.

3

4

5 


\section{Table 4 (on next page)}

Table_4_Effect_of_different_treatments_on_pregnancy_rate_after_pronuclear_embryo_tr ansplantation_in_recipient_sheep_and_lambs_born- $\square$ 
1 Table 4 Effect of different treatments on pregnancy rate after pronuclear embryo transplantation in recipient 2 sheep and lambs born

\begin{tabular}{ccccc}
\hline Group & Recipient & Embryos transferred & Pregnancy rate & Lambs/ewes \\
$5 \mathrm{mg}$ & 45 & $2.5 \pm 0.2(115 / 45)$ & $43.3 \pm 6.1 \%(20 / 45)^{\mathrm{a}}$ & $24 / 45(54.0 \pm 4.0 \%)^{\mathrm{a}}$ \\
Control & 58 & $2.6 \pm 0.1(150 / 58)$ & $25.3 \pm 4.9 \%(14 / 58)^{\mathrm{b}}$ & $15 / 58(27.7 \pm 9.0 \%)^{\mathrm{b}}$ \\
\hline
\end{tabular}

3 Note: different letters in the same column indicate significant difference $(p<0.05)$.

4

5 


\section{Table 5 (on next page)}

Effect of different treatments on morula/blastocyst production after superovulation of donor 
1 Table 5 Effect of different treatments on morula/blastocyst production after superovulation of donor

\begin{tabular}{ccccc}
\hline & Donors & Average Luteum & Average Embryos & Normal embryos \\
\hline $5 \mathrm{mg}$ & 15 & $10.33 \pm 1.37^{\mathrm{a}}$ & $7.80 \pm 1.25^{\mathrm{a}}$ & $7.40 \pm 1.25^{\mathrm{a}}$ \\
Control & 13 & $8.08 \pm 1.13^{\mathrm{a}}$ & $4.08 \pm 0.70^{\mathrm{b}}$ & $3.96 \pm 0.73^{\mathrm{b}}$
\end{tabular}

2 Note: different letters in the same column indicate significant difference $(p<0.05)$.

3

4

5

6

7

8

9

10 
Table 6(on next page)

Table_6_Effect_of_different_treatments_on_pregnancy_rate_after_morula- $\square$ 
1 Table 6 Effect of different treatments on pregnancy rate after morula/blastocyst transplantation in recipient 2 sheep

\begin{tabular}{lllll}
\hline Group & Recipient & Embryos transferred & Pregnancy rate & Lambs/ewes \\
\hline $5 \mathrm{mg}$ & 25 & $1.88 \pm 0.13(47 / 25)^{\mathrm{a}}$ & $72.3 \pm 4.6 \%(18 / 25)^{\mathrm{a}}$ & $19 / 18(105.7 \pm 10.0 \%)^{\mathrm{a}}$ \\
Control & 22 & $1.86 \pm 0.15(41 / 22)^{\mathrm{a}}$ & $54.7 \pm 4.0 \%(12 / 22)^{\mathrm{b}}$ & $14 / 12(116.7 \pm 14.4 \%)^{\mathrm{a}}$
\end{tabular}

3 Note: different letters in the same column indicate significant difference $(p<0.05)$. 